\title{
Revista Brasileira de Enfermagem REBEn \\ Aderência dos Cursos de Graduação em Enfermagem às Diretrizes Curriculares Nacionais
}

\author{
Adherece of Nursing Graduation Courses to the National Curricular Guidelines
}

\author{
Adherencia de los Cursos de Pregrado en Enfermería a las Pautas Curriculares Nacionales
}

\section{David Lopes Neto}

Escola de Enfermagem da Universidade Federal do Amazonas, Manaus, AM.

Elizabeth Teixeira

Curso de Enfermagem da Universidade do Estado do Pará, Belém, PA.

Euclea Gomes Vale

Curso de Enfermagem da Faculdade Católica Rainha do Sertão, Quixadá, CE.

Fátima Scarparo Cunha

Escola de Enfermagem da Universidade Federal do Estado do Rio de Janeiro, RJ.

lara de Moraes Xavier

Universidade de Brasília, DF.

Josicleia Dumêt Fernandes

Escola de Enfermagem da Universidade Federal da Bahia, Salvador, BA.

Kaneji Shiratori

Escola de Enfermagem da Universidade Federal do Estado do Rio de Janeiro, RJ.

Kenya Schimidt Reibnitz

Escola de Enfermagem da Universidade Federal de Santa Catarina, Florianópolis, SC.

Maria Regina Lemes de Sordi

Faculdade de Educação da Universidade de Campinas, SP.

Márcia Barbieri

Escola de Enfermagem da Universidade Federal de São Paulo, SP.

Maria Inês Brandão Bocardi

Faculdade de Enfermagem das Faculdades da Alta Paulista de Tupã, SP.

Este artigo foi extraído do capítulo do livro "A aderência dos cursos de graduação em enfermagem, medicina e odontologia às Diretrizes Curriculares Nacionais", MS e MEC, publicado em 2006.

Submissão: 10/10/2007

Aprovação: 25/10/2007

\section{RESUMO}

Esta investigação teve como objetivo identificar a aderência dos Projetos Pedagógicos dos Cursos de Graduação em Enfermagem (PPC/ENF) às Diretrizes Curriculares Nacionais (DCN) para esses cursos. Trata-se de um estudo descritivo, comparativo, entre os dados presentes nos PPC/ENF e os propostos nas DCN, tendo como base os relatórios dos processos avaliativos conduzidos pelo Instituto Nacional de Ensino e Pesquisa do Ministério da Educação e Cultura e disponibilizados para este estudo. A amostra foi constituída pelos relatórios para fins de reconhecimento e renovação de reconhecimento, realizados no período de 2002 a 2006, relativos a 110 cursos de graduação. Foram relacionados 60 aspectos do instrumento e destes foram selecionados 10 . 0 estudo revelou que o índice de aderência dos cursos de enfermagem às DCN/ENF foi $72 \%$, considerado baixo, o que aponta para a necessidade das escolas/ cursos buscarem melhor vinculação entre a adoção das bases epistemológicas presentes nas DCN/ENF e as propostas nos PPC/ENF.

Descritores: Educação em enfermagem; Diretrizes; Programas de graduação em enfermagem.

\section{ABSTRACT}

The objective of this study was to evaluate the adherence of the Pedagogic Projects of Nursing Graduation Courses (PPC/ENF) to the National Guidelines for the Curriculum of Nursing Graduation Courses (DCN/ENF). It was a descriptive study that compared the information obtained from the reports of the PPC/ENF and the proposals of DCN/ENF, using data collected by INEP/MEC and made available for this study. The data base consisted of all reports from 110 nursing graduation courses that were seeking accreditation or renewal between 2002 and 2006. Sixty aspects of the evaluation were selected and 10. The study reports that the rate of adherence of the nursing courses to the DCN/ENF guidelines was low, 72\%. These findings indicate there is a need for nursing courses/schools to adjust the epistemological bases of the DCN/ENF to the proposals of PPC/ENF.

Descriptors: Nursing education; Guidelines; Education, nursing, diploma programs.

\section{RESUMEN}

Esta investigación tuvo como objetivo identificar la coherencia/adherencia de Proyectos Pedagógicos de Ios Cursos de Pregrado en Enfermería (PPC/PE) con/a las Pautas Curriculares Nacionales para esos cursos (DCN/ENF). Estudio descriptivo, comparativo, entre los datos presentes en los PPC/ENF y los propuestos en las DCN/ENF, teniendo como base los informes de los procesos de evaluación conducidos por el INEP/MEC y puestos a disposición para este estudio. La muestra fue constituida por los informes de evaluación, referentes a los procesos de 110 cursos de pregrado en enfermería para reconocimiento o renovación de reconocimiento de los mismos, en el período de 2002 a 2006. Fueron relaccionados 60 aspectos del instrumento y de estos fueron seleccionados 10. El estudio mostró que el índice de adherencia de los PPC/PE a las DCN/ENF fue de 72\% considerado bajo, lo que apunta para la necesidad de que las escuelas busquen una mejor vinculación entre las bases epistemológicas presentes en las DCN/ENF y las propuestas en los PPC/ENF.

Descriptores: Educación en enfermería; Pautas; Programas de graduación en enfermería.

Lopes Neto D, Teixeira E, Vale EG, Cunha FS, Xavier IM, Fernandes JD, et al. Aderência dos Cursos de Graduação em Enfermagem às Diretrizes Curriculares Nacionais. Rev Bras Enferm 2007 nov-dez; 60(6): 627-34.

\section{INTRODUÇÃO}

A educação superior vem sendo desafiada a romper paradigmas que a colocam na direção de uma formação com pertinência social e coerência com as Diretrizes Curriculares Nacionais (DCN), ou seja, com as necessidades de transformação do processo de formação profissional. 
Por serem processuais, as mudanças na elaboração de novos Projetos Pedagógicos de Cursos (PPC) e na sua implementação vêm evidenciando dificuldades dos cursos na aderência às DCN. Apesar dessas dificuldades, espera-se que, ao longo de um processo reflexivo, dialógico e comprometido com as mudanças exigidas pela sociedade, as Instituições de Ensino Superior (IES) que oferecem cursos de graduação e, particularmente, de enfermagem, devam elaborar seus Projetos Pedagógicos de Cursos (PPC), demonstrando a internalização desse processo pelos atores envolvidos na mudança.

Essa expectativa aponta para a transformação do perfil dos futuros trabalhadores da saúde, por meio da adoção de estratégias dirigidas ao campo da formação e desenvolvimento dos profissionais, construídas com base nos princípios e diretrizes do sistema público de saúde, além de fundamentadas no conceito ampliado de saúde; na utilização de metodologias ativas de ensino-aprendizagem, que considerem o trabalho em saúde como eixo estruturante das atividades; no trabalho multiprofissional e transdisciplinar; na integração entre o ensino e os serviços de saúde; e no aperfeiçoamento da atenção integral à saúde da população.

Nessa perspectiva, simultaneamente ao movimento das IES na redefinição de seus PPC, o Ministério da Educação (MEC) e o Ministério da Saúde (MS), considerando o disposto na Portaria Interministerial № 2.118, de 3/11/ 2005, fortaleceram a parceria, entre ambos, de modo a interferir e potencializar, por meio da avaliação da educação superior, a complexidade dos diversos cenários das práticas em saúde. Esses dois Ministérios, através do Instituto Nacional de Estudos e Pesquisas em Educação Anísio Teixeira (INEP), criaram comissões constituídas por profissionais das áreas de enfermagem, medicina e odontologia, com o objetivo de avaliar a coerência dos cursos de graduação com as $\mathrm{DCN}^{(1)}$.

A comissão daárea de enfermagem, autora do presente estudo, acreditando na capacidade reveladora da avaliação, buscou apreender aspectos da organização didático-pedagógica, expressos nos Projetos Pedagógicos de Cursos (PPC) de Graduação em Enfermagem, submetidos a processos de reconhecimento e renovação e reconhecimento, na sua aderência às DCN/ENF.

Nessa busca, foi formulado o seguinte questionamento: Qual a aderência dos PPC de graduação em enfermagem, às DCN/ENF?

Buscando respostas a esse questionamento, este trabalho tem como objetivo: analisar, tendo por base os relatórios dos processos avaliativos, conduzidos pelo INEP/MEC, a aderência às DCN/ENF, registradas nos PPC de graduação em enfermagem, de IES públicas e privadas que integram o Sistema Federal de Ensino.

No alcance desse objetivo, o presente estudo pretende contribuir para o planejamento e implementação de políticas de formação e inserção profissional do enfermeiro, na perspectiva do Sistema Único de Saúde (SUS).

\section{MARCOS CONCEITUAIS PARA OS NEXOS ENTRE EDUCAÇÃO SUPERIOR, DIRETRIZES CURRICULARES E AVALIAÇÃO}

A Lei de Diretrizes e Bases da Educação Nacional (LDB), Lei nº 9.394 de $1996^{(2)}$, ao definir as diretrizes e bases da educação nacional, explicitou a responsabilidade da União em assegurar o processo avaliativo, a nível nacional, objetivando a definição de prioridades e a melhoria da qualidade do ensino. Na área da saúde, essa Lei possibilitou a concretização, em 07/08/ 2001, do Parecer 1133 do CNE/CES ${ }^{(3)}$, que reforçou a necessidade da articulação entre Educação Superior e Saúde, objetivando a formação geral e específica dos egressos/profissionais, com ênfase na promoção, prevenção, recuperação e reabilitação da saúde. Após esse Parecer, na área da enfermagem, foi aprovada a Resolução CNE/CES No 03 de 7/11/2001(4), que definiu as Diretrizes Curriculares Nacionais para o Curso de Graduação em Enfermagem (DCN/ENF).

Em 14 de abril de 2004, com a Lei $n^{0} 10.861^{(5)}$, foi criado o Sistema Nacional de Avaliação da Educação Superior - SINAES, que tem a qualidade da educação como meta a ser buscada através da avaliação como instrumento de política educacional, além de articular três modalidades de avaliação - a institucional, a de cursos de graduação e a de desempenho do aluno - com regulação da educação superior. Essa Lei imprime, ao sistema de avaliação, um caráter formativo, interdisciplinar e intencional, além de se propor a ter conseqüências para além da regulação.

A avaliação de cursos e de IES aparece como um processo necessariamente contínuo, na medida em que, no Art. 46 da LDB, ficou estabelecido que a autorização e 0 reconhecimento de cursos e 0 credenciamento de IES passaram a ter prazos de vigência limitados, devendose renová-los, periodicamente, mediante processo regular de avaliação.

Esse contexto, tem como direcionamento a ruptura com um currículo mínimo que ignorava ou negava características diversificadas da sociedade brasileira, tais como: complexidade natural e social, heterogeneidade e desigualdades de diversas naturezas. Assim, com o novo paradigma que se impõe o PPC passa a consubstanciar a educação como fenômeno político e social que se propõe a contribuir na formação de cidadãos conscientes de suas responsabilidades sociais e profissionais, engajados na luta por uma sociedade mais justa, digna, igualitária e solidária.

Promover o aprimoramento da qualidade do ensino de graduação nos cursos da saúde importa tornar claro aos diferentes atores interessados na mudança, os novos referenciais que devem ser captados pelos processos de avaliação, a fim de subsidiar não apenas a formulação de políticas públicas, mas para sustentar as decisões que orientam o trabalho pedagógico, que se faz necessário para dar conta das rupturas necessárias ao novo paradigma da formação em saúde.

Possibilita-se, assim, a avaliação da distância entre o pretendido e o executado, a captura das lacunas, das ausências, das contradições existentes. Almeja-se que essa seja um verdadeiro exercício de reflexão sobre as ações do passado, seus impactos no presente e as possibilidades de um futuro mais promissor em termos de resultados educacionais mais densos e socialmente relevantes ${ }^{(6)}$. Esse entendimento evita que se caia no equívoco de reduzir a avaliação da qualidade dos cursos a uma prestação de contas, burocratizada, ao sistema. Se assim a concebermos despotencializamos sua dimensão pedagógica e política.

A questão da avaliação passou a ser peça fundamental na garantia da implementação das DCN/ENF como eixo orientador para a elaboração de PPC inovadores, assegurando a aprendizagem centrada no aluno; a construção de um currículo integrado, onde o eixo da formação passa a ser a prática/trabalho/cuidado de enfermagem; a articulação teoria/prática; as concepções de saúde enquanto condições de vida; a consideração de interpenetração e transversalidade; a concepção de avaliação como instrumento de (re)definição de paradigmas ${ }^{(7-8)}$.

Os PPC configuram, pois, a base de gestão acadêmico-administrativa dos cursos, devendo conter os elementos das bases filosóficas, conceituais, políticas e metodológicas que definem as competências e habilidades essenciais à formação das(os) enfermeiras(os), constituindo-se numa expressão das DCN/ENF.

As DCN/ENF, mais que um documento instituído pelo Conselho Nacional de Educação, norteiam as IES na formação cidadã e profissional da(o) enfermeira(0), na definição dos componentes curriculares essenciais para 0 Curso de Graduação em Enfermagem, na implementação de estágios curriculares supervisionados, na incorporação de atividades complementares e na organização do curso, tendo por base a flexibilização curricular. Além disso, destaca a importância da diversidade de cenários de aprendizagem, com ênfase no Sistema Único de Saúde (SUS) e na realidade loco-regional, para proporcionar a integralidade das ações de qualidade e humanas de enfermagem, devendo, estes elementos, estarem relacionados ao processo de construção do conhecimento sobre o processo saúde-doença, nas diferentes fases do ciclo vital humano $0^{(7,8)}$.

As DCN/ENF possibilitam, destarte, a compreensão da construção coletiva do PPC, bem como a percepção do aluno como sujeito do seu processo de formação, da articulação entre o ensino, a pesquisa e a extensão/ assistência, além de dispor, para as IES, a orientação sobre a criação de mecanismos de aproveitamento de conhecimentos, adquiridos pelo estudante, 
por meio de estudos e práticas independentes, presenciais e/ou à distância a partir de diferentes cenários e experiências de aprendizagem. Elas expressam, pois, conceitos originários dos movimentos por mudanças na educação em enfermagem, explicitando a necessidade do compromisso com princípios da Reforma Sanitária Brasileira e do Sistema Único de Saúde ${ }^{(7)}$.

Essas diretrizes têm como objeto a construção de um perfil acadêmico e profissional para enfermeiras(os) com competências e habilidades, através de perspectivas e abordagens contemporâneas de formação, pertinentes e compatíveis com referenciais nacionais e internacionais. Asua intencionalidade volta-se para o oferecimento de diretrizes gerais para que o processo de formação possa desenvolver a capacidade de aprender a aprender que engloba aprender a conhecer, aprender a fazer, aprender a viver junto e aprender a ser, garantindo a capacitação de profissionais com autonomia e discernimento paraassegurar a integralidade da atenção à saúde com qualidade, eficiência e resolutividade ${ }^{(8)}$.

Esta mudança expressa, sem dúvida, o resultado do impacto provocado pelos dispositivos apresentados pela LDB e as conseqüentes orientações formuladas pelas DCN/ENF na elaboração dos PPC, tendo em vista a realidade nacional e regional. Esse documento legal incitou também, e mais especificamente, a formação de profissionais na área de saúde, tendo em vista a integralidade da atenção à saúde como princípio constitucional norteador da formulação de políticas de saúde. Em relação aos trabalhadores para esse setor, cabendo ao SUS ordenar a formação de recursos humanos na área de saúde, o que está definido nas Leis Orgânicas de Saúde (LOS) - Lei 8.080, de 19 de setembro de 1990 e Lei 8.142, de 28 de dezembro de 1990(9).

Nas LOS, o título relativo à formação de recursos humanos destaca que a política para os trabalhadores da área da saúde deve cumprir o objetivo de organizar um sistema formador em todos os níveis de educação, inclusive de pós-graduação, além de programas de permanente aperfeiçoamento de pessoal. Assim sendo, reiteram as LOS os princípios e diretrizes do SUS, já dispostos no código supremo brasileiro, reafirmando que a efetivação das políticas públicas de saúde dar-se-á pela reorientação da política de recursos humanos no SUS e, por conseguinte, na reformulação dos currículos das instituições de ensino superior por meio de Diretrizes Curriculares adequadas às necessidades do SUS.

A elaboração de um PPC é uma ação intencional de pessoas, instituição, de grupos, com um sentido explícito, com um compromisso definido coletivamente. Por isso, todo PPC é, também, um projeto político por estar intimamente articulado ao compromisso sócio-político e com os interesses reais e coletivos da população majoritária, não podendo estar alijado do contexto social, uma vez que ele é histórica e socialmente determinado. $\mathrm{Na}$ dimensão pedagógica reside a possibilidade da efetivação da intencionalidade da escola, que é a formação do cidadão participativo, responsável, compromissado, crítico e criativo. Pedagógico, no sentido de se definir as ações educativas e as características necessárias às escolas de cumprirem seus propósitos e sua intencionalidade.

Buscar a aderência entre as DCN/ENF e os PPC, portanto, significa compreender a realidade do processo de formação na enfermagem, nas suas diferentes concepções e práticas, haja vista a complexidade e 0 entendimento da incompletude dos saberes.

\section{METODOLOGIA}

O presente estudo optou por uma abordagem quantitativa de situações empiricamente observáveis, com a checagem e a interação de informações e conhecimentos contidos no material investigado, possibilitando a compreensão dos dados em sua intensividade e extensividade. Pois, conforme assinalam "[...] a quantidade é uma dimensão da qualidade do social e dos sujeitos sociais, marcados em suas estruturas, relações e produções pela subjetividade [...]"(10).

Para a definição da amostra, foram considerados os relatórios para fins de reconhecimento e renovação de reconhecimento, realizados no período de 2002 a 2006, disponibilizados pelo INEP/MEC, relativos a 110 cursos de graduação: 94 privados e 16 públicos..

No primeiro momento, foram selecionados 60 aspectos do instrumento de avaliação utilizado nos processos avaliativos do INEP/MEC, que poderiam abordar temas apresentados nas DCN/ENF, a saber: Coordenação de curso: atuação, apoio didático, titulação, regime de trabalho, efetiva dedicação; Concepção do curso: objetivos, perfil do egresso; Currículo: coerência com objetivos, coerência com perfil, coerência com as DCN, adequação da metodologia, inter-relação das disciplinas; Sistema de avaliação: coerência, procedimentos, auto-avaliação; Estágio supervisionado: acompanhamento, relação aluno-professor, níveis de atenção, integração ensino-serviço; TCC: acompanhamento, relação aluno-professor; Atividades complementares: diversidade de cenários; Titulação do corpo docente; Experiência: tempo de magistério superior, tempo de exercício fora do magistério; Adequação da formação: às disciplinas ; Formação: pedagógica; Regime de trabalho/TI, TP e horista; Estímulos: produção científica, participação em eventos, formação e atualização; Dedicação: carga semanal; Relação aluno-docente: média por docente; Relação disciplina-docente: média por docente, proximidade temática; Atividades: orientação didática, de estágio supervisionado, atividades científicas discentes; Acervo: livros, periódicos, informatização, base de dados, multimídias; Unidade Básica de Saúde: espaço, equipamentos, serviços; Unidade de Saúde da Família: espaço, equipamento, serviços; Hospitais: espaço, equipamento, serviços.

Com base nesta lista de 60 aspectos, foi levantado um conjunto de hipóteses explicativas relacionadas a cada um deles, o que foi imprescindível para se analisar a potência de cada aspecto para revelar aderência dos PPC às DCN/ENF.

Tendo como base os marcos teóricos e legais adotados, bem como um intenso trabalho de reflexão, 11 aspectos foram selecionados, a partir dos 60 aspectos diretamente vinculados às DCN.

Os 11 aspectos do instrumento de avaliação que abordam temas indicados nas DCN/ENF, e considerados mais relevantes estão apresentados a seguir: Perfil do egresso; Adequação da metodologia de ensino à concepção do curso; Inter-relação das disciplinas na concepção e execução do currículo; Coerência do sistema de avaliação do processo ensino-aprendizagem com a concepção do curso; Existência de mecanismos efetivos de acompanhamento e de avaliação do estágio; Diversidade de cenários de aprendizagem; Estímulos (ou incentivos) profissionais; Docentes com orientação de estágio supervisionado, de trabalho de conclusão de curso ou de atividades complementares; Unidades básicas de saúde - Serviços; Unidade de saúde da família - Serviços; Hospitais de cuidados secundários e terciários - Serviços.

Os 60 e os 11 aspectos contidos nos instrumentos de avaliação dos cursos de graduação em enfermagem constituíram os índices de aderência $\mathrm{I}_{60} \mathrm{el}_{11}$

Com base na análise de dados, por medida de associação, chegou-se a um conjunto de 10 aspectos que foram considerados como capazes de expressar maior aderência às DCN/ENF. Esta lista dos aspectos do instrumento de avaliação que abordam temas fortemente indicados nas DCN/ ENF, a seguir apresentada: Concepção do curso; Objetivos do curso; Perfil do egresso; Currículo; Coerência do currículo com os objetivos do curso; Coerência do currículo com o perfil desejado do egresso; Adequação da metodologia de ensino à concepção do curso; Inter-relação das disciplinas na concepção e execução do currículo; Coerência do sistema de avaliação do processo ensino-aprendizagem com a concepção do curso; Procedimentos de avaliação do processo ensino-aprendizagem.

Assim, o corpus de análise constituiu-se dos dados oriundos da aplicação do $I_{60}$ e dos dados oriundos da aplicação do $I_{10}$. 0 estudo, apesar de não envolver danos a seres humanos, passou pelo crivo do INEP/MEC, que o autorizou e disponibilizou os dados necessários à sua realização.

\section{RESULTADOS}

\subsection{Análise dos aspectos do $i_{60}$}

O primeiro trabalho de análise foi sobre os 110 cursos de enfermagem e 
foi realizado com base em alguns aspectos contidos nos instrumentos de avaliação, apresentados e analisados a seguir. (gráfico 1)

Nos aspectos Concepção do curso, Objetivos e Perfil do Egresso as IES privadas apresentaram bons índices, podendo, no entanto, indicar 0 movimento formal de atendimento às DNC/ENF (regulação apenas). Já nas IES federais, respaldadas na autonomia que possuem, percebe-se um movimento mais lento de atendimento às DNC/ENF, fruto, talvez, de processos de negociação interna sobre seus significados.

Se a existência de experiências colegiadas potencializa o debate sobre o PPC, é importante destacar que a defesa da importância da reflexão e da participação não deve servir para acobertar movimentos de resistência às mudanças na formação, com subseqüente repercussão nos serviços de saúde. Instituições públicas de ensino não podem esquecer de que há interesses sociais que não podem ser afetados por processos de discussão que se estendem indefinidamente e, algumas vezes, para evitar que as mudanças de paradigma ocorram. Gráfico 2

Nos aspectos Adequação do currículo e Adequação da metodologia de ensino à concepção do curso, $79 \%$ das Universidades Federais foram consideradas como Regulares, sendo que as IES privadas tiveram $58 \%$ de Muito Bom nete quesito. Gráfico 3

No que se refere à Avaliação do processo ensino aprendizagem e seus procedimentos, ela é julgada Regular (64\%) nas Federais, e Muito Bom (59\%) nas IES privadas, sendo que, nos procedimentos avaliatórios, foi observado, nas Federais, o conceito Regular (64\%) e Muito Bom (68\%) nas IES privadas. No setor privado, a existência de mecanismos de recuperação da aprendizagem foi bastante citada. Importa interrogar se estes mecanismos estão ligados a um esforço de humanização da avaliação ou, contraditoriamente, se democratizam estes espaços para promover a manutenção dos alunos em seus espaços, com o viés econômico sendo definidor da política institucional.

Um olhar integrado sobre as 3 dimensões encontradas nos instrumentos possibilitou uma melhor compreensão do contexto que envolve as IES, ora sob avaliação. Permitiu também que se explore as contradições inerentes ao processo de mudança paradigmática.

Defende-se, aqui, que boa qualidade do ensino é resultante de um conjunto de aspectos que se interpenetram. Para bem fazer aquilo que é preciso fazer, necessita-se dispor de condições objetivas mínimas para o trabalho. Se isso é aceitável em qualquer circunstância, torna-se imprescindível quando se pretendem mudanças nas convencionais formas de ensinar/aprender/avaliar.

Assim, para dar conta de uma organização didático-pedagógica inovadora, é necessário contar com atores que viabilizem esta nova forma de organização do trabalho pedagógico e, neste sentido, um olhar sobre as condições de trabalho parece indispensável. Gráfico 4

Quanto ao regime de trabalho, as Federais tiveram o conceito de Muito Bom (86\%), enquanto que nas IES privadas este índice oscila de Regular (52\%) a Muito Fraco/Fraco (23\%). Estes índices contrastaram com os obtidos pelas IES privadas na dimensão organização didático-pedagógica.

Formas de organização didático-pedagógica diferenciadas com uso de

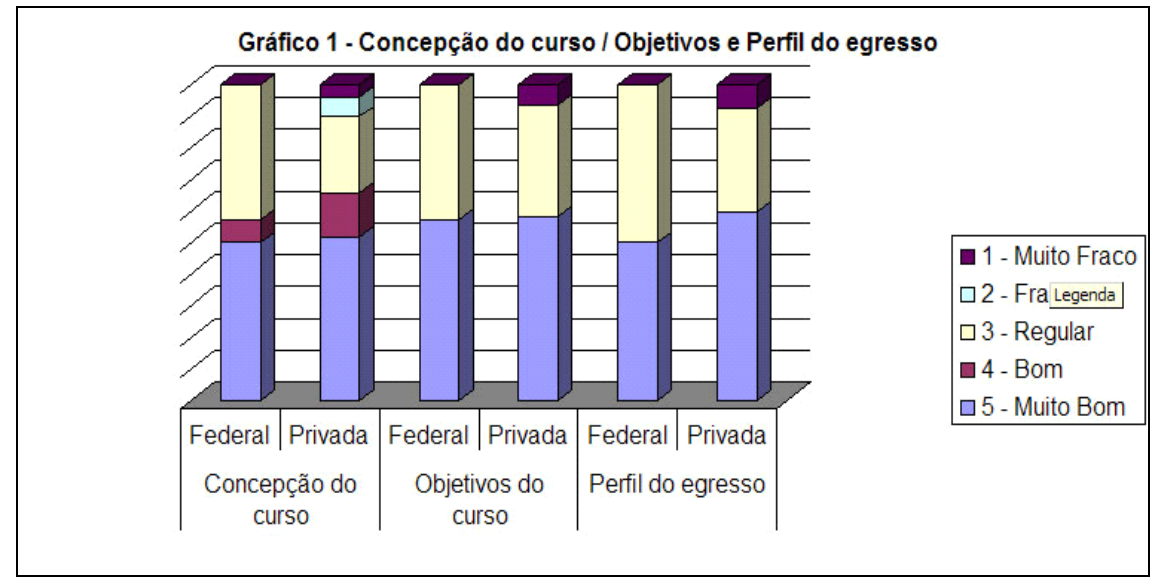

Fonte: INEP/MEC - 2002/2006.

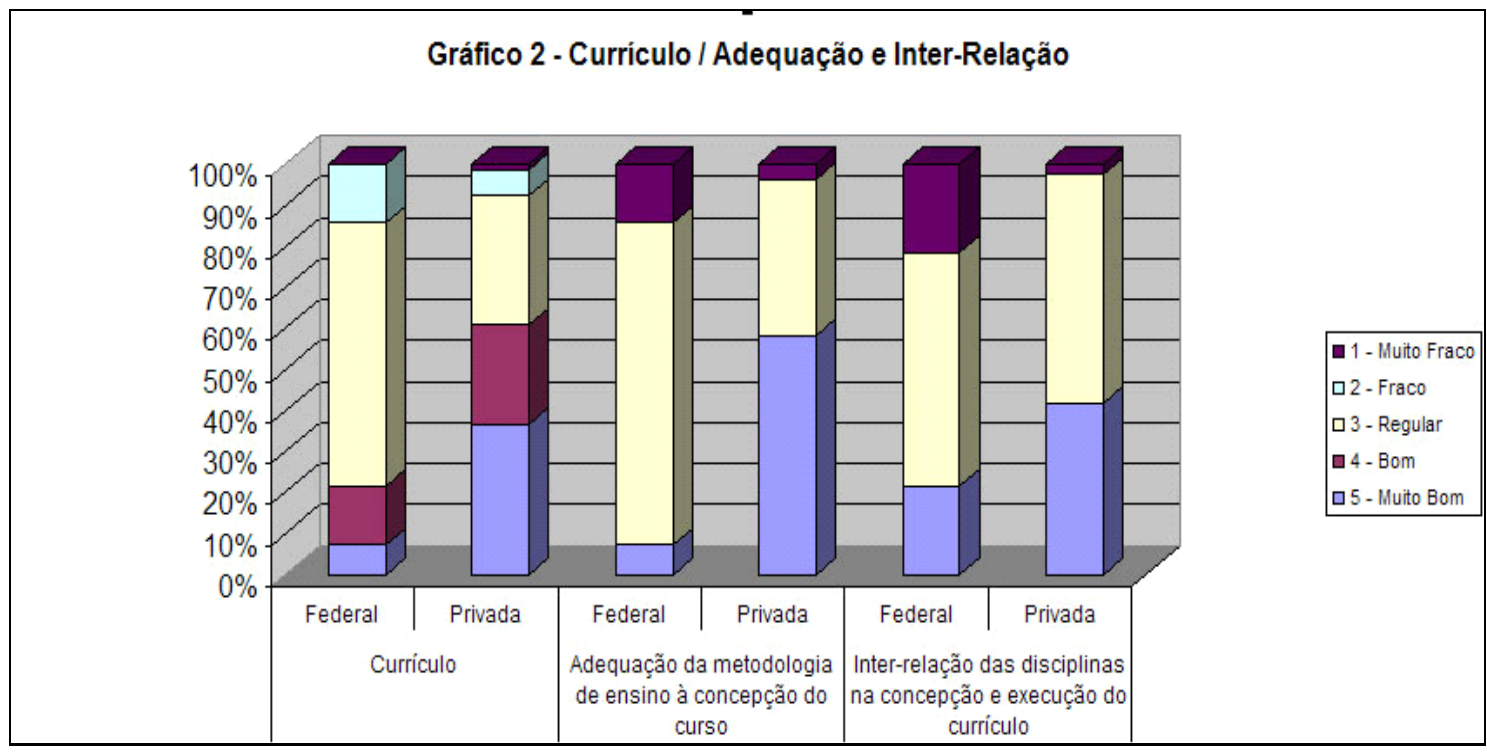

Fonte: INEP/MEC - 2002/2006. 


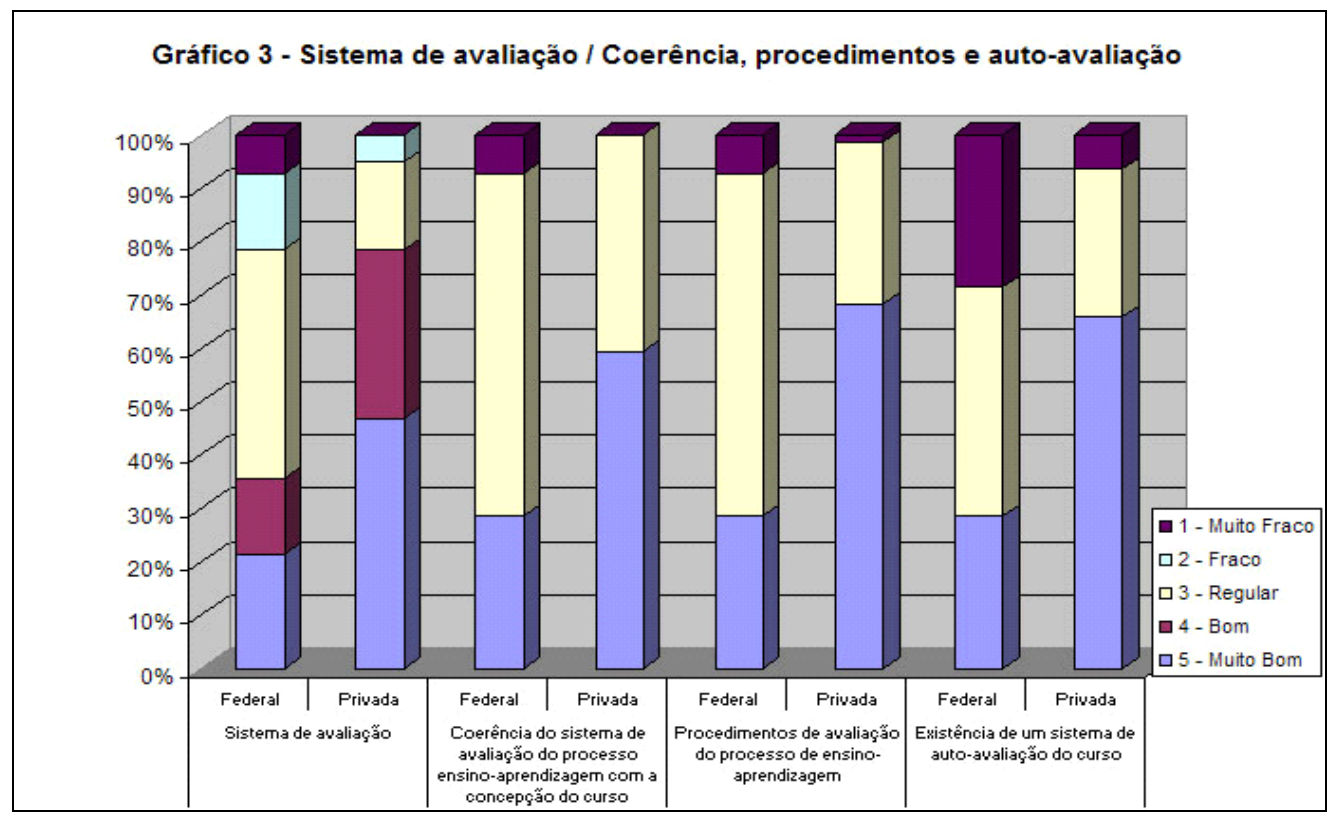

Fonte: INEP/MEC - 2002/2006.

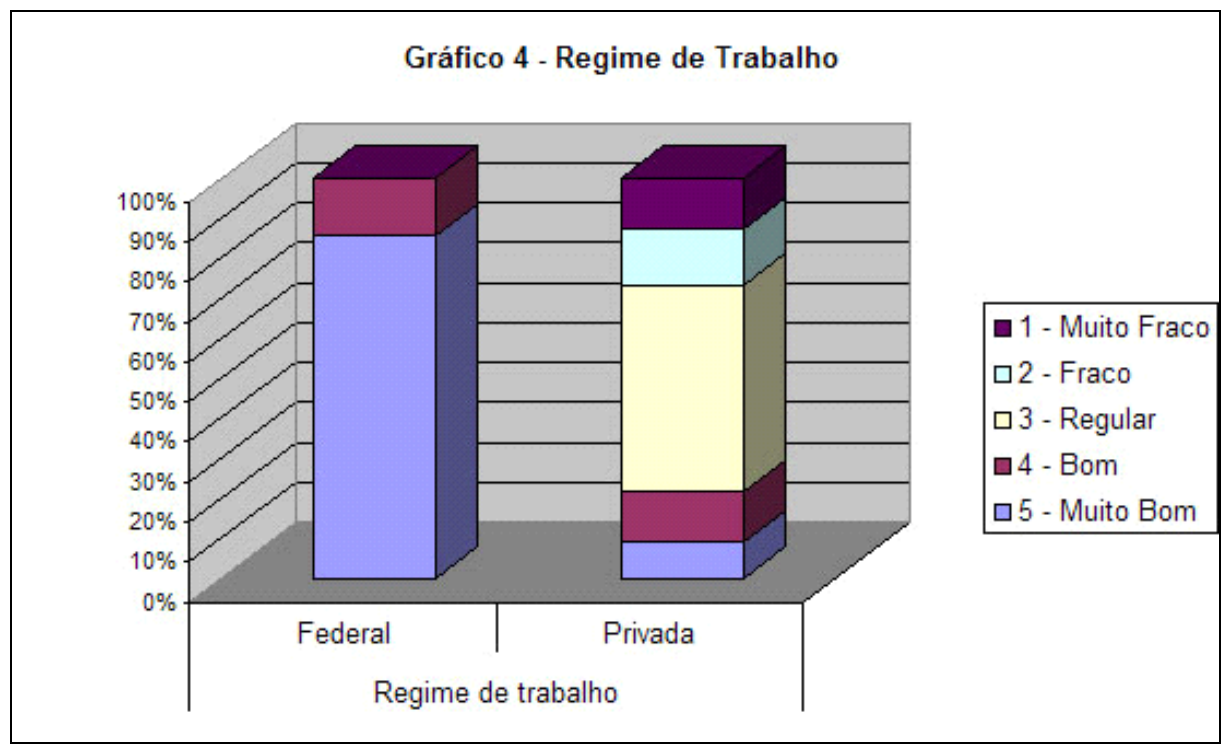

Fonte: INEP/MEC - 2002/2006.

metodologias ativas apontam para um trabalho docente exaustivo, pois cabe aos professores a mediação e a sustentação da inovação. Isto implica em tempo e dedicação. Como fazê-lo em regimes de contratação horista? Com quem construir PPC coletivos? Como monitorar a implantação deste projeto que é favorecida pelos encontros do grupo para reflexão se o grupo não puder estar junto? Se uma IES tem índices considerados regulares neste campo, como compreender possa estar tão bem situado na organização didático-pedagógica? Quem são estes professores que devem formar egressos dos cursos de enfermagem a partir das DNC/ENF? Qual seu perfil, repertório de experiências para assumirem a tarefa docente? Gráfico 5

Em relação ao Tempo de magistério superior, foi observado que nas Federais este tempo foi explicitado como Muito Bom (43\%) e nas IES privadas como Muito Fraco (78\%). Em contrapartida, o indicador Tempo de exercício profissional fora do magistério foi considerado Muito Bom (96\%) nas IES privadas, contra 50\% de Muito Bom nas federais. Nestas, não há como desconsiderar as políticas previdenciárias que têm induzido à aposentadoria precoce. Em decorrência disto, são contratados professores substitutos, sem experiência no magistério superior e com tempo de contrato delimitado. Dificilmente pode-se esperar deles uma maior aderência a um PPC.

Nas IES privadas, chama-se atenção para o que poderia ser considerado fragilidade (baixa experiência no magistério superior e alta experiência profissional), vir a se transformar em possibilidade, desde que associada ao apoio pedagógico. Aausência de experiência pedagógica prévia pode propiciar uma abertura a aprendizagens mais contemporâneas que incluem metodologias ativas e que são fundamentais para promover a aderência às DCN/ENF, com repercussão na realidade sanitária. Gráfico 6

A Dedicação ao curso, foi considerada Bom em $57 \%$ nas Federais, enquanto nas IES privadas foi Regular (42\%). Nas IES privadas, a predominância do regime horista restringe, sobretudo, a dedicação dos docentes a outras atividades complementares e quase que naturaliza a existência de vínculos com outras Instituições. Evidentemente, isso compromete outros indicadores.

No aspecto docentes com orientação didática de alunos, foi 


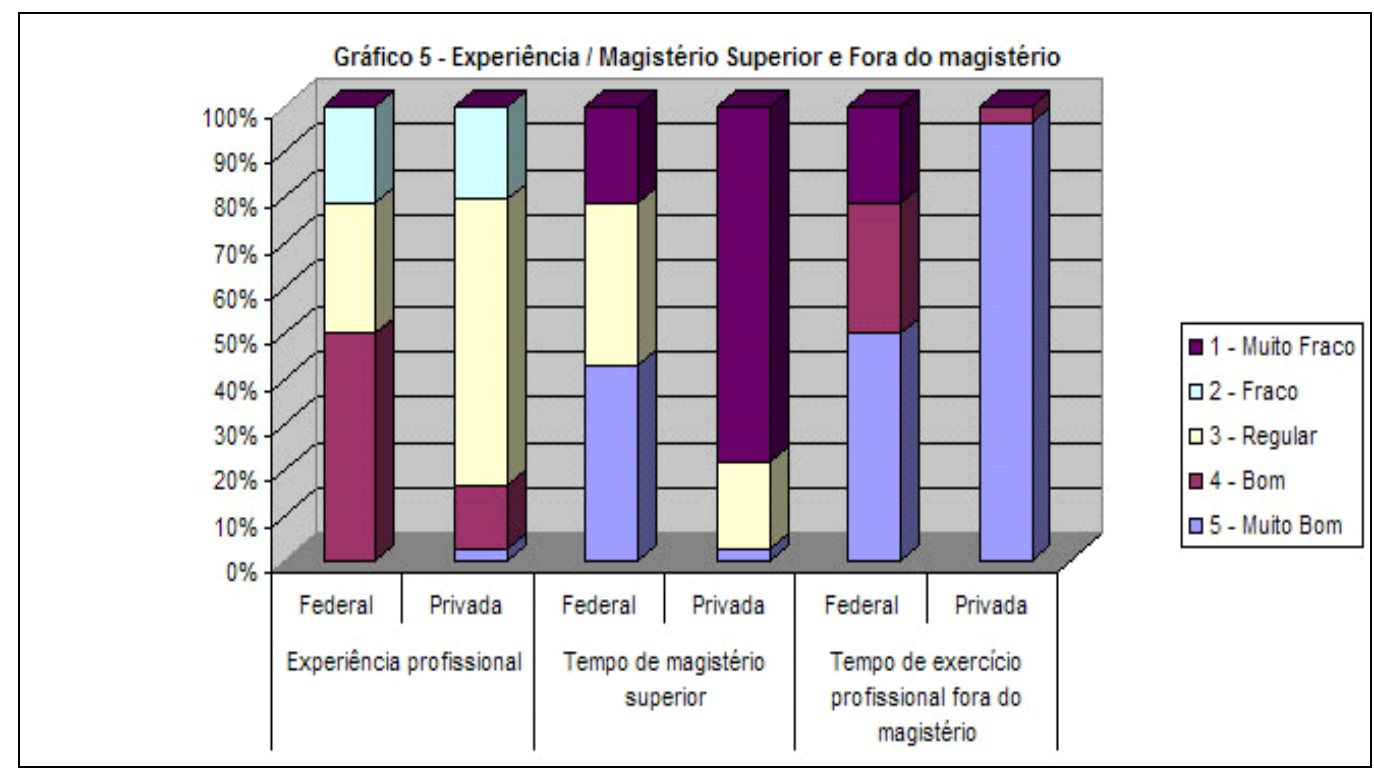

Fonte: INEP/MEC - 2002/2006.

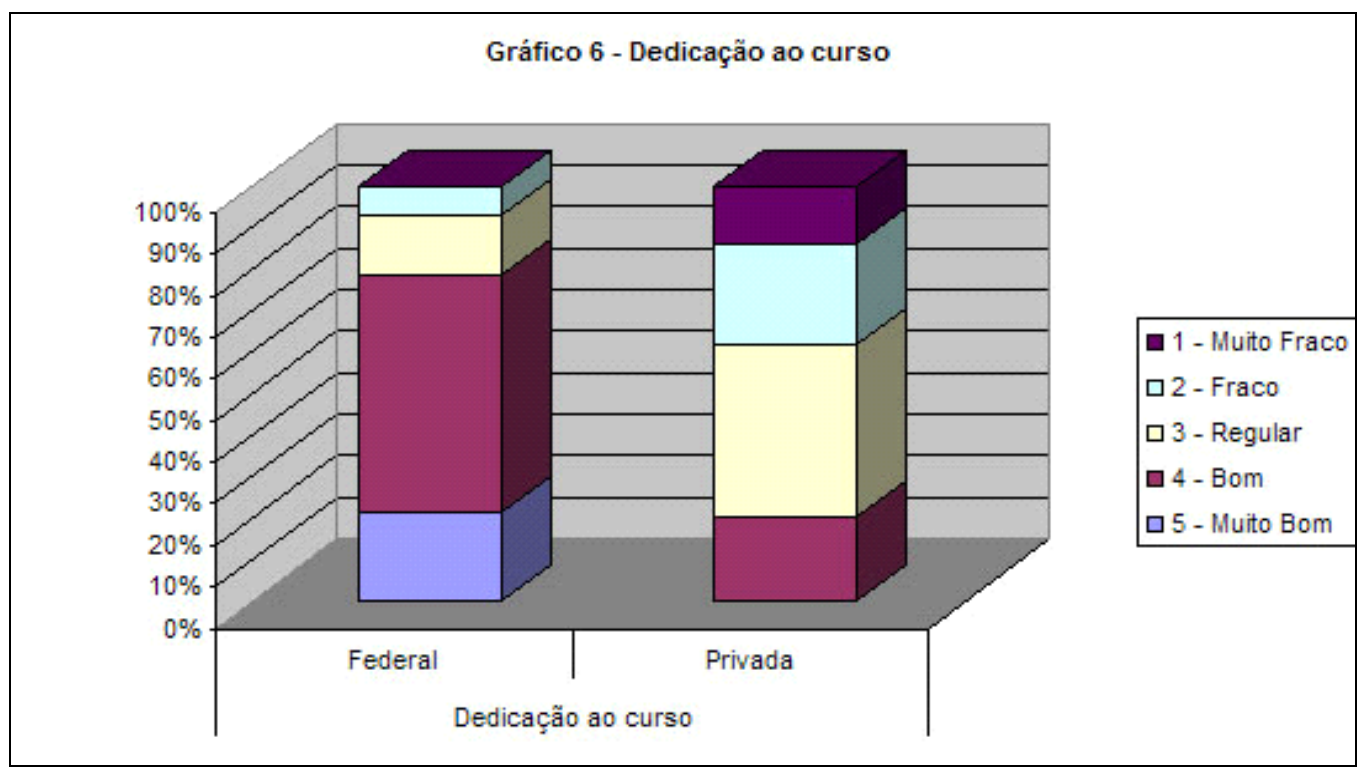

Fonte: INEP/MEC - 2002/2006

constatado Muito Bom (50\%) nas Federais e Muito Fraco (44\%) nas IES privadas. Para docentes com orientação de ECS, de TCC ou de Atividades Complementares, nas Federais foi Muito Bom (64\%) e nas IES privadas Muito Bom (37\%) + Muito Fraco (30\%). Para docentes com orientação de bolsistas, nas Federais foi Muito Bom (100\%) e nas IES privadas foi Muito Bom (57\%) + Muito Fraco (43\%).

Se há flagrantes problemas quando os indicadores são cruzados (condições objetivas de sustentação de trabalho pedagógico diferenciado), a pergunta é: quem encarna os PPC nos cursos privados e em que bases os conceitos de avaliação se sustentam rigorosamente? Que evidências têm sido usadas pelos avaliadores para exprimir a adesão que deve estar presente nos cursos?

Políticas regulatórias são facilmente assimiladas pelos gestores dos cursos, mas mostram-se frágeis e sujeitas a rápidas distorções quando submetidas ao choque da realidade. Os avaliadores, por sua vez, devem desenvolver certa habilidade para triangular os dados obtidos nas diferentes fontes de coleta, a fim de não criarem uma ilusão de qualidade nos cursos ou uma ilusão de eficienticismo das IES (cumprem metas, sem mudar paradigmas). Coloca-se um véu sobre os dados e isso enviesa a interpretação, o que afeta, sobremaneira, a definição de políticas publicas.

É de grande importância o papel do coordenador para orquestrar os esforços do coletivo do curso, tornando possível um PPC afinado com as DCN/ENF, revelados nos aspectos atuação do coordenador do curso e efetiva dedicação do coordenador à administração e à condução do curso.

Neste aspecto, é importante destacar que não se pode contentar com a aparência do fenômeno. A analise linear da carga horária do coordenador pode levar a algumas distorções, pois esta não expressa isoladamente a capacidade do coordenador de gerar ou induzir processos produtivos coletivos de gestão do curso/PPC. Também, é necessário considerar que a carga horária contratada do coordenador não expressa, necessariamente, a efetiva dedicação às funções de gestão do curso, ou seja, o tempo destinado à docência produtiva no exercício da gestão acadêmica.

Se a figura do coordenador é decisiva para mobilizar as mudanças rumo ao PPC, esta responsabilidade não pode recair no trabalho individual do 
coordenador, posto que a saúde do PPC dependa dos acordos coletivos, dos pactos que vão sendo formulados processualmente. De que vale um coordenador com 40 horas, se todos os professores do curso são horistas ou provisórios? Defende-se, aqui, que a qualidade da gestão do coordenador deve ser referenciada à sua capacidade de articular as forças que sustentam o PPC, em lugar de ser 'medida' pela capacidade demonstrada de preencher adequadamente os formulários para o sistema.

\subsection{Análise dos aspectos do $i_{60}, i_{11}$ e $i_{10}$}

A análise quantitativa de aderência dos cursos de enfermagem às $\mathrm{DCN}$ ENF foi realizada com base em aspectos contidos nos instrumentos de avaliação. Como se pode observar, as maiores médias foram alcançadas nos índices $\mathrm{I}_{11}$ e $\mathrm{I}_{60}$ e a menor média no $\mathrm{Ic}_{10}$ (Tabela 1).

Tabela 1. Distribuição dos valores dos índices de aderência dos cursos às DCN/ENF 2002-2006.

\begin{tabular}{cccccc}
\hline Índices & Cursos Avaliados & Média & DP & Mínimo & Máximo \\
\hline $\mathrm{I}_{60}$ & 110 & 0,73 & 0,12 & 0,43 & 0,94 \\
$\mathrm{I}_{60}$ & 110 & 0,53 & 0,18 & 0,17 & 0,87 \\
$\mathrm{I}_{11}$ & 110 & 0,76 & 0,16 & 0,27 & 1,00 \\
$\mathrm{I}_{11}$ & 110 & 0,59 & 0,25 & 0,09 & 1,00 \\
$\mathrm{I}_{10}$ & 110 & 0,72 & 0,22 & 0,10 & 1,00 \\
$\mathrm{I}_{10}$ & 110 & 0,48 & 0,36 & 0,00 & 1,00 \\
\hline Fonte: $I$ INEP/MEC $-2002 / 2006$. & & & &
\end{tabular}

Tabela 2. Distribuição das médias dos valores dos índices de aderência dos cursos às DCN/ENF, segundo aspecto único da avaliação 2002-2006.

\begin{tabular}{ccccc}
\hline Índices & Muito Fraco & Regular & Muito Bom & Total \\
\hline $\mathrm{I}_{60}$ & 0,62 & 0,71 & 0,80 & 0,73 \\
$\mathrm{IC}_{60}$ & 0,39 & 0,48 & 0,65 & 0,53 \\
$\mathrm{I}_{11}$ & 0,60 & 0,74 & 0,85 & 0,76 \\
$\mathrm{IC}_{11}$ & 0,39 & 0,53 & 0,76 & 0,59 \\
$\mathrm{I}_{10}$ & 0,41 & 0,67 & 0,92 & 0,72 \\
$\mathrm{IC}_{10}$ & 0,14 & 0,35 & 0,83 & 0,48 \\
\hline Fonte: INEP/MEC - 2002/2006. & & &
\end{tabular}

O Ic $c_{10}$ tem distribuição com a maior dispersão de valores, quando analisado pela distância entre o valor mínimo e o valor máximo. As menores variâncias foram observadas nos índices $\mathrm{I}_{60}$ e $\mathrm{I}_{11}$. A maior dispersão dos valores dos índices $\mathrm{I}_{10}, \mathrm{IC}_{11}$ elc ${ }_{10}$ pode ser devido às medidas dicotômicas que compõem, mas também pela maior capacidade de discriminar a aderência do curso às DCN/ENF (Tabela 2).

$\mathrm{Na}$ Tabela 2, para cada conceito, as médias mostram a incorporação das DCNs. No grupo de conceito MB, utilizando-se os índices, percebe-se que o I10, o I11 e o Ic10 expressam as médias mais altas de incorporação das DCN/ENF. E assim para cada grupo de conceitos.

As diferenças das médias dos grupos de cursos classificados pelo aspecto único da avaliação "muito fraco", "regular" e "muito bom" foram estatisticamente significantes (Tabela 2).

As médias do grupo que atenderam completamente as DCN/ENF. foram $13 \%, 35 \%, 15 \%, 43 \%, 37 \%$, e $137 \%$ maiores do que no grupo "regular" para os índices $\mathrm{I}_{60}, \mathrm{IC}_{60}, \mathrm{I}_{11}$ e $\mathrm{IC}_{11} \mathrm{I}_{10}$ e $\mathrm{I}_{10}$, respectivamente.

\section{CONSIDERAÇÕES FINAIS}

Um dos desafios que impulsionou a realização deste estudo foi a possibilidade de uma aproximação, pela via da avaliação realizada pelo INEP/MEC, com a qualidade da formação acadêmica dos profissionais de enfermagem, egressos de cursos de graduação, modalidade bacharelado.

O estudo revelou que o índice de aderência dos cursos de enfermagem às DCN/ENF foi de $72 \%$, índice considerado abaixo das expectativas esperadas, uma vez que, após 5 anos de vigência das DCN/ENF, já era de se esperar uma maior identificação dos cursos com os postulados preconizados por essas diretrizes.

A tarefa da avaliação dos cursos não é simples e deve ser objeto de capacitação permanente. No caso dos cursos da saúde, isto implica na atenção também aos significados que os atores (avaliadores e avaliados) atribuem às novas e contra hegemônicas concepções que se tenta viabilizar. Não se deve desconhecer que o esforço de apropriação dos pressupostos é processual, não linear e submetido a constantes embates, frutos das concepções de qualidade da formação em saúde.

Cabe, também, ao avaliador, reconhecer e valorizar os esforços do grupo que tenta inovar e que encontra limite nas condições objetivas de trabalho oferecidas institucionalmente ou nas formas de organização dos sistemas de saúde da região em que se insere o curso.

O olhar dos avaliadores para os PPC marca, de alguma maneira, as formas de produção do relatório, ampliando seu viés regulatório ou emancipatório. Talvez permitindo exercitar uma "regulação orientada para emancipação". Ou seja, à tarefa de regulação deve se associar o sentido pedagógico-politico da avaliação, estimulando a comunidade do curso a compreender as contradições do processo de implantação de um processo de formação inovador.

Foi considerado, também, que a diversidade de cenários de aprendizagem é essencial para superar a formação centrada no conhecimento fisiopatológico e desagregada da realidade sócio-sanitária e da prestação do cuidado na rede SUS. Entendeu-se, também, que as condições de trabalho docente, particularmente, sua qualificação permanente, são mediadores importantes da possibilidade de desenvolver os processos de ensino e aprendizagem coerentes com as DCN/ENF. A formação pretendida para o enfermeiro implica no trabalho docente no estágio curricular supervisionado, trabalho de conclusão de curso e atividades complementares. Por fim, os espaços de aprendizagem nas unidades básicas de saúde, unidades de saúde da família e hospitais secundários e terciários são considerados essenciais para atender as DCN/ENF

A construção dos Projetos Pedagógicos (PPC) dos Cursos de Graduação em Enfermagem no Brasil, mobilizados a partir da nova Lei de Diretrizes e Bases da Educação - LDB determinou um movimento desafiador na comunidade acadêmica. Contudo, estas discussões não se configuram como um movimento novo, pois, há algum tempo, a formação em Enfermagem vem sendo discutida em suas bases teórico-filosóficas, alinhadas com a pedagogia crítica, pois seus atores acreditam numa práxis de enfermagem, compreendida como atividade objetiva e transformadora da realidade natural e social, que implica em certo grau de conhecimento da realidade que transforma e das necessidades que satisfaz.

Frente aos dados analisados, a presente investigação defende a necessidade de uma vinculação estreita entre a adoção, pelos cursos de graduação, das bases epistemológicas presentes nas DCN/ENFe a qualidade do processo de aprendizagem previsto nos PPC.

Porém, não se pode ignorar que o SINAES, como política de Estado, preconiza que a qualidade acadêmica não pode ser considerada de forma dissociada da responsabilidade social da IES e do curso de graduação, por não se tratar de um atributo abstrato, mas de juízo valorativo construído socialmente.

Com base nos resultados e nas considerações apresentadas neste estudo, destacam-se como perspectivas e desafios:

- Apreensão das bases epistemológicas das DCN/ENF, com vistas ao domínio filosófico e pedagógico dos princípios, diretrizes, estratégias e ações consagradas pela Resolução CES/CNE 03/2001;

- Transformação das DCN/ENF em PPC, com garantia da identidade institucional, das diversidades do sistema de ensino federal e regional/cultural e da responsabilidade social, sem perder a aderência a qualidade da formação acadêmica do futuro enfermeiro;

- Implantação e implementação dos PPC, como processo de construção coletiva, que produza ruptura paradigmática com modelos antagônicos ao 
pautado pelas DCN/ENF;

- Criação e disseminação de cenários acadêmicos, promovidos e financiados pela parceria dos Ministérios da Saúde e Educação, que envolvam os vários atores deste processo: gestores, docentes, discentes, técnicos, administrativos e docentes avaliadores do INEP;

- Compromisso com o desenvolvimento do SINAES, ampliando a participação social em todas as modalidades avaliativas, na busca da conquista de uma educação superior cidadã, igualitária e equânime.

- Definição e compromisso institucional dos Ministérios da Saúde e da Educação e das IES com agenda positiva que possibilite troca de experiências em relação à mudança paradigmática de modelos de aprendizagem: fim do currículo mínimo e adoção das DCN/ENF, em sua plenitude, nos PPC.

Mediante as reflexões aqui realizadas, foi destacada a capacitação dos avaliadores como um dos grandes desafios para o fortalecimento do SINAES, reforçando a discussão teórico-filosófica sobre a mudança de paradigma no processo pedagógico e na concepção de saúde, articulados aos princípios estabelecidos no Sistema Único de Saúde, resgatando a formação de profissionais Enfermeiros, voltada para a integralidade dos problemas de saúde da população brasileira, mais especificamente, loco - regional, para que a assistência à saúde oferecida seja contextualizada e resolutiva.

Como já mencionado anteriormente, os resultados deste trabalho representam recortes da problemática enfocada, sem, contudo, ter a pretensão de tratá-la na sua totalidade. Para tanto, seria necessária uma análise profunda, também, dos Projetos Pedagógicos Institucionais (PPI) e dos Planos de Desenvolvimento Institucionais (PDI), além da introdução de outras técnicas de pesquisa como a entrevista, a observação, dentre outras.

Para concluir, é necessário explicitar que este estudo não pretende ser um estudo acabado, nem indicar caminhos a serem percorridos pelas instituições/escolas/cursos para alcançarem as transformações necessárias, pois, nesse caso, estaria se desprezando a complexidade do atuar em educação/saúde e a necessária multireferencialidade desse agir. Trata-se apenas da apresentação de parte de uma realidade dos processos avaliativos conduzidos pelo INEP/MEC, evidenciando a aderência/não aderência das escolas/cursos às DCN/ENF, apontando indicativos para as políticas públicas de formação e inserção profissional da(0) enfermeira(o), na perspectiva do Sistema Único de Saúde.

\section{REFERÊNCIAS}

1. Ministério da Educação e Cultura (BR), Ministério da Saúde (BR). A aderência dos cursos de graduação em enfermagem, medicina e odontologia às diretrizes curriculares nacionais. Brasília (DF): Ministério da Saúde; 2006.

2. Brasil. Lei no 9.394, de 20 de dezembro de 1996. Dispõe sobre as bases e diretrizes da educação nacional. Brasília (DF): Ministério da Educação e Cultura; 1996.

3. Brasil. Conselho Nacional de Educação Câmara da Educação Superior. Parecer $n^{\circ} 1.133$, de 07 de agosto de 2001. Dispõe sobre as Diretrizes Curriculares da Medicina, Enfermagem e Nutrição. Brasília (DF): Ministério da Educação e Cultura; 2001.

4. Brasil. Conselho Nacional de Educação, Câmara da Educação Superior. Parecer $n^{0}$ 3, de 7 de novembro de 2001 - institui as Diretrizes Curriculares Nacionais do Curso de Graduação em Enfermagem. Brasília (DF): Ministério da Educação e Cultura; 2001.

5. Brasil. Lei $\mathrm{n}^{0} 10.861$ de 14 de abril de 2004. Institui o Sistema Nacional de Avaliação da Educação Superior - SINAES. Brasília (DF): Ministério da Educação e Cultura; 2004.

6. Sordi MRL. Avaliação universitária: mecanismo de controle, de competição e exclusão ou caminho para a construção da autonomia, da cooperação e da inclusão? In: Veiga IPA, Naves
MLP, organizadoras. Currículo e avaliação na educação superior. Araraquara (SP): Junqueira \& Marin; 2005.

7. Fernandes JD, Ferreira SLA, Oliva DSR, Santos MP, Costa HOG. Estratégias para a implantação de uma nova proposta pedagógica na Escola de Enfermagem da Universidade Federal da Bahia. Rev Bras Enferm 2003; 56(4): 392-5.

8. Fernandes JD, Xavier IM, Ceribelli MIPF, Bianco MHC, Maeda D, Rodrigues MVC. Diretrizes Curriculares e estratégias de implantação de uma nova proposta pedagógica. Rev Esc Enferm USP 2005; 30(4); 443-9.

9. Brasil. Lei $n^{0} 8.080$ de 20 de setembro de 1990. Dispõe sobre as condições para a promoção, proteção e recuperação da saúde, a organização e o funcionamento dos serviços correspondentes e da outras providencias. Brasília (DF): Ministério da Saúde; 1990.

10. Deslandes SF, Assis SG. Abordagens quantitativa e qualitativa em saúde: 0 diálogo das diferenças. In: Minayo MC, Deslandes $\mathrm{SF}$, organizadores. Caminhos do pensamento: epistemologia e método. Rio de Janeiro (RJ): FIOCRUZ, 2003.

11. Reibnitz KS, Prado M. Inovação e educação em Enfermagem. Florianópolis (SC): Cidade Futura; 2006. 